$10-2017$

Mini-craniotomy under local anesthesia for chronic subdural hematoma: An effective choice for elderly patients and for patients in a resource-strained environment

Shaikh Danish Mahmood

Muhammad Waqas

Mirza Zain Baig

Aneela Darbar

Follow this and additional works at: https://ecommons.aku.edu/pakistan_fhs_mc_mc

Part of the Neurology Commons, Neurosurgery Commons, and the Surgery Commons 


\title{
Mini-Craniotomy Under Local Anesthesia for Chronic Subdural Hematoma: An Effective Choice for Elderly Patients and for Patients in a Resource-Strained Environment
}

\author{
Shaikh Danish Mahmood ${ }^{1}$, Muhammad Waqas $^{2}$, Mirza Zain Baig ${ }^{1}$, Aneela Darbar ${ }^{2}$
}

BACKGROUND: Mini-craniotomy for chronic subdural hematoma (CSDH) is associated with lower rates of recurrence. However, the procedure is performed mostly with the patient under general anesthesia (GA) and therefore frequently requires an intensive care unit (ICU) facility, especially in the elderly population. Because of the unavailability of ICU beds, and to avoid GA, we started to perform this procedure with the patient under local anesthesia (LA).

MATERIALS AND METHODS: This was a retrospective medical chart review conducted in the section of Neurosurgery at the Aga Khan Hospital in Karachi, Pakistan. The study duration was 1 year. We included patients aged 55 years or older undergoing surgery for CSDH. Clinical characteristics, hospital stay, and recurrence rates were compared between 2 groups, local versus general anesthesia.

RESULTS: Thirty-five patients underwent minicraniotomy for CSDH in the study period. Sixteen patients underwent mini-craniotomy under LA versus 19 patients for GA. Median age for the LA group was 67 years compared with 70 years in the GA group. Four patients from the LA group experienced postoperative complications versus 7 from the GA group. Only one patient in the LA group required an ICU bed in the postoperative period. There was no recurrence in LA group. The overall recurrence was $2.86 \%$.
CONCLUSIONS: Mini-craniotomy for CSDH under LA is an equally effective procedure compared with minicraniotomy under GA. In addition, it minimizes the risks of GA in the elderly population and obviates the need of a postoperative ICU bed. It also reduces operative time and hospital stay as compared with GA.

\section{INTRODUCTION}

he incidence of chronic subdural hematoma (CSDH) is approximately 3 per 100,000 , with a considerable increase noted in the elderly population. ${ }^{\mathrm{I}}$ Although there is little doubt that surgical intervention for symptomatic patients is advantageous, considerable controversy surrounds the choice of ideal surgical approach. ${ }^{2}$ Despite the fact that CSDH drainage is a frequently performed procedure, we do not have level I evidence on comparison of different surgical approaches. A retrospective review of consecutive mini-craniotomy procedures for subdural hematoma patients by Van Der Veken et al. ${ }^{3}$ has highlighted the technical superiority of the procedure in comparison with burr-hole drainage. Recent articles, however, favor burr-hole drainage over twist-drill craniostomy and craniotomy. ${ }^{\mathrm{I}}$ One of the major reasons for this preference is the ease with which it can be performed under both local anesthesia (LA) and general anesthesia (GA) and low associated morbidity. In contrast to studies on burr-hole drainage, there is a deficiency of literature focusing on mini-craniotomy. In a systematic review by Lega et al., ${ }^{4} 3$ studies describing

\section{Key words \\ - Burr-hole drainage \\ - Chronic subdural hematoma \\ - Local anesthesia \\ - Mini-craniotomy}

\section{Abbreviations and Acronyms}

CSDH: Chronic subdural hematoma

GA: General anesthesia

GCS: Glasgow Coma Scale

ICU: Intensive care unit

LA: Local anesthesia
From the ${ }^{\mathbf{1}}$ Medical College and ${ }^{\mathbf{2}}$ Section of Neurosurgery, Division of Surgery, The Aga Khan University Hospital, Karachi, Pakistan

To whom correspondence should be addressed: Aneela Darbar, M.D.

[E-mail: aneela.darbar@aku.edu]

Citation: World Neurosurg. (2017) 106:676-679

http://dx.doi.org/10.1016/j.wneu.2017.07.057

Journal homepage: www.WORLDNEUROSURGERY.org

Available online: www.sciencedirect.com

1878-8750/\$ - see front matter (c) 2017 Elsevier Inc. All rights reserved. 
mini-craniotomy for SDH were mentioned..$^{4-7}$ Their study compared 6222 cases of burr-hole drainage with only 36r cases of craniotomies, and there was no comparison of craniotomies under GA and under LA. ${ }^{4}$

In a country in which neurocritical care facilities and ventilator beds are limited, it is very important to find techniques that can help minimize the need of postoperative ventilation. Faced with the problem of limited number of ventilator beds, we recently have adapted the technique of mini-craniotomy under LA, which theoretically carries most of the advantages of a burr hole (avoidance of GA) and those of mini-craniotomy (less recurrence/ residual). To objectively look at the differences of mini-craniotomy under LA with other surgical approaches for the drainage of subdural hematoma, we decided to review our data.

The objective of the study was to compare mini-craniotomy for CSDH under LA versus the same procedure performed under GA, in terms of operative time, frequency of residual or recurrence needing second surgery, length of stay in the intensive care unit (ICU), and total length of hospital stay.

\section{MATERIAL AND METHODS}

This retrospective medical chart review was conducted in the section of Neurosurgery at the Aga Khan Hospital Karachi, Pakistan. The study duration was January I, 20I0, to September 3I, 2016. We included all the patients aged 55 years or older undergoing surgery for the CSDH in the study period. Patients with missing data were excluded.

\section{Surgical Technique}

The surgery is performed with the patient in the supine position. A dedicated anesthesia nurse is assigned to the patient to continuously monitor the vitals. Preoperative antibiotics are given for gram-positive coverage, and well beta blockers are readily available in case the blood pressure is greater I6o systolic. First, $\mathrm{I}-2 \mathrm{mg}$ of intravenous midazolam is given. The patient's head is placed on a ring, and we consciously maintain a neutral position. After shaving a strip of the patient's hair, we mark a linear incision at maximum thickness of subdural hematoma and infiltrate it with $2 \%$ lidocaine without epinephrine. A craniotomy of approximately $3 \times 3 \mathrm{~cm}$ is performed with a single burr hole. The dura is opened in a cruciate manner, and margins are coagulated. All the membranes of hematoma are opened under vision with the help of loupes. Subdural space is irrigated. Bone is reattached with plates, and a subgaleal drain is placed for postoperative drainage.

\section{Data Collection}

Medical records of the eligible patients were obtained from medical record department after approval of ethical review committee. Data were collected with the help of a pro forma. This pro forma had sections on demographic and baseline clinical features including signs and symptoms of the disease, operative details, and details of postoperative course. Variables studied included time of surgery, type of anesthesia, duration of surgery, surgical approach, blood loss, and type of drain and use of irrigation. We also recorded time to ambulation, number of days with drain, stay in the ICU, special care, and total length of stay. We also looked at postoperative improvement in the neurologic status, based on preoperative and postoperative examination of level of consciousness, speech slurring, and hemiparesis. Findings of a repeat computed tomography scan, when done, were recorded. Need of a second surgery, urinary tract infection, pneumonia, pulmonary embolism, deep venous thrombosis, and mortality were other recorded variables.

\section{Analysis}

Data were recorded on SPSS, version I9 (IBM Corp., Armonk, New York, USA). We calculated percentage and proportions for categorical data and means with standard deviation for continuous data. In cases in which the data did not have a normal distribution median and ranges were estimated, an independent $t$ test was applied to compare continuous data, whereas the $\chi^{2}$ test was used for categorical data. Independent $t$ tests were used for comparison of means and Mann-Whitney $U$ tests for medians. P value equal or less than 0.05 was regarded statistically significant. We compared in-hospital mortality, redo surgery, recurrence of SDH, and length of hospital stay between different surgical groups by use of the $\chi^{2}$ test.

\section{RESULTS}

Thirty-five patients were included in the study. Sixteen of these patients underwent mini-craniotomy under LA and ig under GA. The majority of patients presented with headaches, with or without other symptoms indicative of mass effect. Other presentations were drowsiness, hemiparesis, or confusion. Surgery was indicated mainly by hemiparesis in ro cases, headache in 6 cases, loss of consciousness in 3 cases, seizures in 2 cases, and by drowsiness or weakness and confusion in the remaining I4. Demographic details and baseline clinical characteristics are provided in Table 1.

The mean length of surgery from start of incision to dressing was $68.63 \pm 27.6$ I minutes in patients who underwent craniotomy under LA. In patients who underwent craniotomy under GA, the mean length of surgery was Ior \pm 51.86 minutes.

A total of II patients experienced postoperative complications. Seven of the patients in the GA group experienced pneumonia, pleural effusion, rebleed, low hemoglobin, coma, fever, and generalized seizures. The 4 patients in the LA group experienced fever, infections, and deep venous thrombosis. The $P$ value for association between the type of surgery and the postsurgical improvement of presenting symptoms of aphasia, hemiparesis, and altered consciousness was 0.157. There were 3 cases of mortality, of whom 2 were patients operated under LA and I was operated under GA. Both of the patients who were operated under LA had end-stage renal disease, with poor Glasgow Coma Scale (GCS) scores, which remained unchanged after surgery. The patients soon died. The patient operated under GA similarly had chronic kidney disease, with acute renal failure, and unstable hemodynamics and subsequently died after no improvement in GCS score.

The list of complications and outcomes in the 2 groups is provided in Table 2. One patient from the GA group experienced a recurrence of subdural hematoma, which was treated with another 
Table 1. Demographic and Clinical Characteristics of Patients Undergoing Mini-Craniotomy for Chronic Subdural Hematoma

\begin{tabular}{|c|c|c|c|}
\hline Variables & $\begin{array}{l}\text { Under Local } \\
\text { Anesthesia }\end{array}$ & $\begin{array}{l}\text { Under General } \\
\text { Anesthesia }\end{array}$ & $P$ Value \\
\hline Sample, $n$ & 16 & 19 & \\
\hline Male, $n$ & 10 & 15 & \\
\hline Median age, years & $67(55-84)$ & 70.26 (57-82) & \\
\hline Current smokers & 2 & 2 & 0.618 \\
\hline Diabetes mellitus & 7 & 2 & 0.020 \\
\hline Hypertension & 12 & 16 & 0.228 \\
\hline $\begin{array}{l}\text { Ischemic heart } \\
\text { disease }\end{array}$ & 1 & 5 & 0.118 \\
\hline $\begin{array}{l}\text { Bilateral subdural } \\
\text { hematoma }\end{array}$ & 2 & 2 & 0.900 \\
\hline Hemiparesis & 7 & 2 & 0.025 \\
\hline Headache & 3 & 6 & 0.387 \\
\hline Drowsiness & 4 & 7 & 0.452 \\
\hline $\begin{array}{l}\text { Median preoperative } \\
\text { GCS }\end{array}$ & $15(7-15)$ & $12(3-15)$ & $\begin{array}{l}\text { Independent } \\
t \text { test: } 0.084 \\
\text { Mann-Whitney } \\
U \text { test: } 0.078\end{array}$ \\
\hline $\begin{array}{l}\text { Surgery time in } \\
\text { minutes (median) }\end{array}$ & $\begin{array}{c}65.5 \text { (mean } \\
68.63 \text { ) }\end{array}$ & 75 (mean 101) & $\begin{array}{l}\text { Independent } \\
t \text { test: } 0.040 \\
\text { Mann-Whitney } \\
U \text { test: } 0.051\end{array}$ \\
\hline $\begin{array}{l}\text { Hospital stay in days } \\
\text { (median) }\end{array}$ & 5 (mean 6.56) & 5 (mean 8.37) & $\begin{array}{l}\text { Independent } \\
t \text { test: } 0.533 \\
\text { Mann-Whitney } \\
U \text { test: } 0.546\end{array}$ \\
\hline
\end{tabular}

mini-craniotomy. On follow-up, none of the patients from LA group showed any recurrence. The average period of hospital stay for patients who underwent craniotomy under GA was 5.I7 days, and the average period of ICU stay was I.8I days. For patients who underwent craniotomy under LA, average period of hospital stay was 6.56 days and average period of ICU stay was I.5 days. The P value for ICU stay independent $t$ test was 0.495 . An association between the type of surgery and postoperative complications was observed, as well as an association between type of surgery and occurrence of pneumonia, with $\mathrm{P}$ values of $0.03 \mathrm{I}$ and 0.033 , respectively.

\section{DISCUSSION}

$\mathrm{CSDH}$ is one of the most commonly encountered neurosurgical problems. Its incidence increases proportionately with age, and with increasing average age the prevalence of $\mathrm{CSDH}$ is expected to increase. ${ }^{8-10}$ According to a recent estimate incidence of $\mathrm{CSDH}$ in patients aged between 70 and 79 years is around 20.6 per Ioo,00o/year. ${ }^{\text {II }}$ Treatment of $\mathrm{CSDH}$ in this age range is further complicated by multiple comorbidities found in these
Table 2. Complications and Outcomes of Mini-Craniotomy for

Chronic Subdural Hematoma

\begin{tabular}{|c|c|c|c|}
\hline Variable & $\begin{array}{l}\text { Under Local } \\
\text { Anesthesia }\end{array}$ & $\begin{array}{c}\text { Under General } \\
\text { Anesthesia }\end{array}$ & $P$ Values \\
\hline $\begin{array}{l}\text { Median follow-up, } \\
\text { months }\end{array}$ & 4 & 3 & \\
\hline Improvement & 14 & 15 & 0.157 \\
\hline $\begin{array}{l}\text { Improvement based } \\
\text { on postoperative } \\
\text { examination } \\
\text { (speech, LOC, } \\
\text { hemiparesis) }\end{array}$ & 11 & 8 & \\
\hline Recurrence & 0 & 1 & \\
\hline Reoperation & 0 & 1 & \\
\hline Mortality & 2 & 1 & 0.464 \\
\hline $\begin{array}{l}\text { Postoperative } \\
\text { pneumonia }\end{array}$ & 1 & 2 & 0.033 \\
\hline Urosepsis & 0 & 0 & \\
\hline $\begin{array}{l}\text { Deep venous } \\
\text { thrombosis }\end{array}$ & 1 & 1 & \\
\hline Need of ICU & 1 (medical reasons) & 6 & 0.062 \\
\hline
\end{tabular}

patients, such as hypertension, diabetes mellitus, and ischemic heart disease. A significant percentage of these patients are on antiplatelet drugs as well. ${ }^{3}$ Thus, whenever these patients develop CSDH, the probability of requiring an ICU ventilator bed becomes very high. However, the situation of availability of ventilator beds in developing countries is miserable. Compared with 20 ICU beds per Ioo,0oo in the United States, developing countries such as Sri Lanka has I.6 per and Uganda I per Io,oo, ooo population. ${ }^{\mathrm{I} 2}$ However, we could not find local data.

One of the treatment options for $\mathrm{CSDH}$ has been burr-hole drainage of subdural hematoma with the patient under LA. ${ }^{\text {I3 }}$ This has been advocated widely in the literature but carries a high rate of recurrence up to $60 \% .^{3, \mathrm{I} 4}$ In a recent article, Van Der Veken et al. ${ }^{3}$ showed the superiority of mini-craniotomy over burr-hole drainage of CSDH.

In this article, we have described early results of our technique of mini-craniotomy under LA. Performing a mini-craniotomy with the patient under LA carries most of the advantages of a burr hole (avoidance of GA) and those of mini-craniotomy (less recurrence/residual hematoma). ${ }^{3}$ We also thought that this would reduce operative time and length of hospital stay without the patient requiring an ICU ventilator bed. This study supports our belief. Postoperative complications occurred in 4 patients operated under LA compared with 7 patients operated under GA. The complications of patients ranged from fever, infections, and deep venous thrombosis in patients operated under LA to pneumonia, pleural effusion, coma, and need for tracheostomy in patients operated under 
GA. Only I of 16 patients in the LA group required a ventilator in the ICU compared with 6 of is in the GA group. Only one patient in the current series had a recurrence. This patient was operated under GA. The overall rate of recurrence was significantly lower $(2.86 \%)$ compared with international data on burr hole drainage $(4.6 \%-\mathrm{I} 6 \%)^{\mathrm{I} 5-18}$ and other surgical modalities (I4.6\%). ${ }^{\text {I9 }}$ We also observed that all cases of mortality, regardless of type of anesthesia, were associated with chronic renal disease.

Through this study, we wanted to introduce the technique of mini-craniotomy under LA for CSDH. However, there are several limitations of the data as well. It was a retrospective study, and the sample size was small. The differences in outcomes may be influenced by differences in preoperative GCS. However, in our study, the difference in preoperative GCS between the 2 groups was not statistically significant. Moreover, the size of the 2 groups was not comparable. Still, we strongly believe that the study carries a strong message favoring the use of mini-craniotomy under LA.

\section{CONCLUSIONS}

Decreasing the need for ICU facilities and postoperative ventilation in elderly patients with $\mathrm{CSDH}$ is vital in areas in which such resources are limited more often than not. It seems that this can be accomplished by performing a mini-craniotomy for CSDH under LA, as it reduces the need for ICU. Patients operated under LA have shown to not only have shorter periods of ICU stay, if any, but also shorter periods of stay in the hospital and shorter surgery lengths. It is especially of note that this procedure diminishes the risk of postoperative complications in elderly patients as well as recurrence and necessity of reoperation. Compared with other treatment modalities, such as mini-craniotomy under GA, it is certainly a promising alternative.

\section{REFERENCES}

I. Regan JM, Worley E, Shelburne C, Pullarkat R, Watson JC. Burr hole washout versus craniotomy for chronic subdural hematoma: patient outcome and cost analysis. PLoS One. 2015;I0:eoII5085.

2. Cenic A, Bhandari M, Reddy K. Management of chronic subdural hematoma: a national survey and literature review. Can J Neurol Sci. 2005;32: 5OI-506.

3. Van Der Veken J, Duerinck J, Buyl R, Van Rompaey K, Herregodts P, D'Haens J. Minicraniotomy as the primary surgical intervention for the treatment of chronic subdural hematoma-a retrospective analysis. Acta Neurochir. 2014;156:98I-987.

4. Lega BC, Danish SF, Malhotra NR, Sonnad SS, Stein SC. Choosing the best operation for chronic subdural hematoma: a decision analysis. J Neurosurg. 2010;113:615-62I.

5. Kwon TH, Park YK, Lim DJ, Cho TH, Chung YG, Chung HS, et al. Chronic subdural hematoma: evaluation of the clinical significance of postoperative drainage volume. J Neurosurg. 2000;93: 796-799.

6. Miele VJ, Sadrolhefazi A, Bailes JE. Influence of head position on the effectiveness of twist drill craniostomy for chronic subdural hematoma. Surg Neurol. 2005;63:420-423.

7. Tanikawa M, Mase M, Yamada K, Yamashita N, Matsumoto T, Banno T, et al. Surgical treatment of chronic subdural hematoma based on intrahematomal membrane structure on MRI. Acta Neurochir. 200I;I43:6I3-6I8.
8. Yang W, Huang J. Chronic subdural hematoma: epidemiology and natural history. Neurosurg Clin N Am. 2017;28:205-2I0.

9. Toi H, Kinoshita K, Hirai S, Takai H, Hara K, Matsushita N, et al. Present epidemiology of chronic subdural hematoma in Japan: analysis of 63,358 cases recorded in a national administrative database [E-pub ahead of print]. J Neurosurg. http://dx.doi.org/I0.3I7I/2016.9.JNSI6623, accessed July 9, 2017.

Io. Uno M, Toi H, Hirai S. Chronic subdural hematoma in elderly patients: is this disease benign? Neurol Med Chir (Tokyo). http://dx.doi.org/Io.2176/ nmc.ra.2016-0337, accessed July 9, 2017.

II. Karibe H, Kameyama M, Kawase M, Hirano T, Kawaguchi T, Tominaga T. Epidemiology of chronic subdural hematomas. No Shinkei Geka. 20II;39:II49-II53 [in Japanese].

12. Adhikari NK, Fowler RA, Bhagwanjee S, Rubenfeld GD. Critical care and the global burden of critical illness in adults. Lancet. 2010;376: I339-I346.

I3. Santarius T, Kirkpatrick PJ, Kolias AG, Hutchinson PJ. Working toward rational and evidence-based treatment of chronic subdural hematoma. Clin Neurosurg. 2009;57: II2-I22.

I4. Sambasivan M. An overview of chronic subdural hematoma: experience with 2300 cases. Surg Neurol. I997;47:418-422.

15. Khadka NK, Sharma GR, Roka YB, Kumar P, Bista P, Adhikari D, et al. Single burr hole drainage for chronic subdural haematoma. Nepal Med Coll J. 2008;10:254-257.
I6. Kuroki T, Katsume M, Harada N, Yamazaki T, Aoki K, Takasu N. Strict closed-system drainage for treating chronic subdural haematoma. Acta Neurochir. 200I;I43:I04I-I044.

I7. Matsumoto K, Akagi K, Abekura M, Ryujin $\mathrm{H}$, Ohkawa M, Iwasa N, et al. Recurrence factors for chronic subdural hematomas after burr-hole craniostomy and closed system drainage. Neurol Res. I999;2I:277-280.

I8. Sarnvivad P, Chiewchanvechakul W, Chumnanvej S. Chronic subdural hematoma: drainage vs. no drainage. J Med Assoc Thai. 20II;94: I352-I356.

I9. Weigel R, Krauss J, Schmiedek P. Concepts of neurosurgical management of chronic subdural haematoma: historical perspectives. $\mathrm{Br} J$ Neurosurg. 2004;I8:8-I8.

Conflict of interest statement: The authors declare that the article content was composed in the absence of any commercial or financial relationships that could be construed as a potential conflict of interest.

Received 11 January 2017; accepted 11 July 2017

Citation: World Neurosurg. (2017) 106:676-679. http://dx.doi.org/10.1016/j.wneu.2017.07.057

Journal homepage: www.WORLDNEUROSURGERY.org Available online: www.sciencedirect.com

1878-8750/\$ - see front matter (C) 2017 Elsevier Inc. All rights reserved. 